\title{
The last instar larva and pupa of Ora depressa (Coleoptera: Scirtidae), a marsh beetle with underwater pupation
}

\author{
María L. LIBONATTI ${ }^{1,2)}$, Gabrielle JORGE ${ }^{3)}$, Miguel ARCHANGELSKY ${ }^{4)} \&$ Mariano C. MICHAT ${ }^{1,2)}$ \\ 1) Universidad de Buenos Aires, Facultad de Ciencias Exactas y Naturales, Departamento de Biodiversidad y Biología Experimental, Entomología, \\ Buenos Aires, Argentina; e-mail: libonatti.marialaura@gmail.com \\ 2) CONICET - Universidad de Buenos Aires, Instituto de Biodiversidad y Biología Experimental y Aplicada - CONICET (IBBEA), Buenos Aires, \\ Argentina \\ 3) Coordenação de Pesquisas em Biodiversidade, Instituto Nacional de Pesquisas da Amazônia, Manaus, Amazonas, Brazil \\ 4) Laboratorio de Investigaciones en Ecología y Sistemática Animal (LIESA), CIEMEP (CONICET-UNPSJB), Esquel, Chubut, Argentina
}

Accepted:

$25^{\text {th }}$ September 2018

Published online: $24^{\text {th }}$ October 2018

\begin{abstract}
In this contribution we describe and illustrate for the first time, detailed morphology and chaetotaxy of the last instar larva and the pupa of Ora depressa (Fabricius, 1801), and provide diagnostic characters and information on its biology. The last instar larva of $O$. depressa exhibits the characters traditionally recognized as diagnostic of the genus, i.e. the tip of the mandible obtuse, and the fourth maxillary palpomere long, almost as long as third palpomere. Ora depressa is characterized by a broadly elliptical body, which is widest at the metanotum, being brownish testaceous in color with several brown spots, having the dorsal surface mostly covered with numerous grooved scale-like setae and also several ungrooved scale-like setae, hair-like setae, club-like setae and pore-like sensilla distributed in a specific pattern, and the femur and tibiotarsus bearing a row of natatorial setae. The last instar larva of Ora depressa can be distinguished from those of the other known species of the genus by lobes of clypeolabrum being as long as wide and socket bristles with 2-6 inner teeth. The pupa of $O$. depress $a$ differs from those of the other known species of the genus in the absence of pronotal horns and by the place where pupation occurs. Ora depressa pupates underwater, hanging from water's surface with the aid of the laterally expanded pronotum which bears hydrophobic setation along the lateral margins.
\end{abstract}

Keywords. Coleoptera, Scirtidae, marsh beetles, larva, pupa, morphology, chaetotaxy, Neotropical Region

\section{Introduction}

Scirtidae or marsh beetles are the most speciose family of Scirtoidea: they comprise about 70 genera and over 1,800 species described worldwide (LibonatTi \& RUTA 2018). Scirtid larvae are usually found in various kinds of aquatic ecosystems, like marshes, lowland ditches, ponds, microhabitats within rivers and streams, phytotelmata, and groundwater. They are notable due to their multi-segmented antennae, a character unique among Coleoptera larvae. The morphology of immature stages of Scirtidae remains among the least studied within aquatic beetles. At the moment, the larvae of only 18 genera (25\%) represented by 90 species $(5 \%)$ and the pupae of only 11 genera $(15 \%)$ represented by
24 species $(1 \%)$ have been described so far (OsTEN-SACKEN 1862; Friedenreich 1883; Picado 1913; KraAtz 1918; GoOD 1924; Hudson 1934; BeERBower 1943; BeIer 1949; BerTRAND 1964; Kitching \& Allsopp 1987; StRibling \& Young 1990; Hannappel \& Paulus 1987, 1991, 1997; Yoshitomi 1997, 2001, 2005, 2012; ZwICK 2007, 2011; ZwICK \& HeCHT 2008; Zwick \& ZWICK 2008a, b, c, 2010; RUTA \& YosHitomi 2010; WATTS 2014). It is worth noting that the species with known immatures are mainly from the Western Palearctic, Australian, and Oriental Regions.

The present contribution focuses on the larva and pupa of a species of Ora Clark, 1865, a pantropical genus including ca. 60 species. Though the adults of Ora have been 

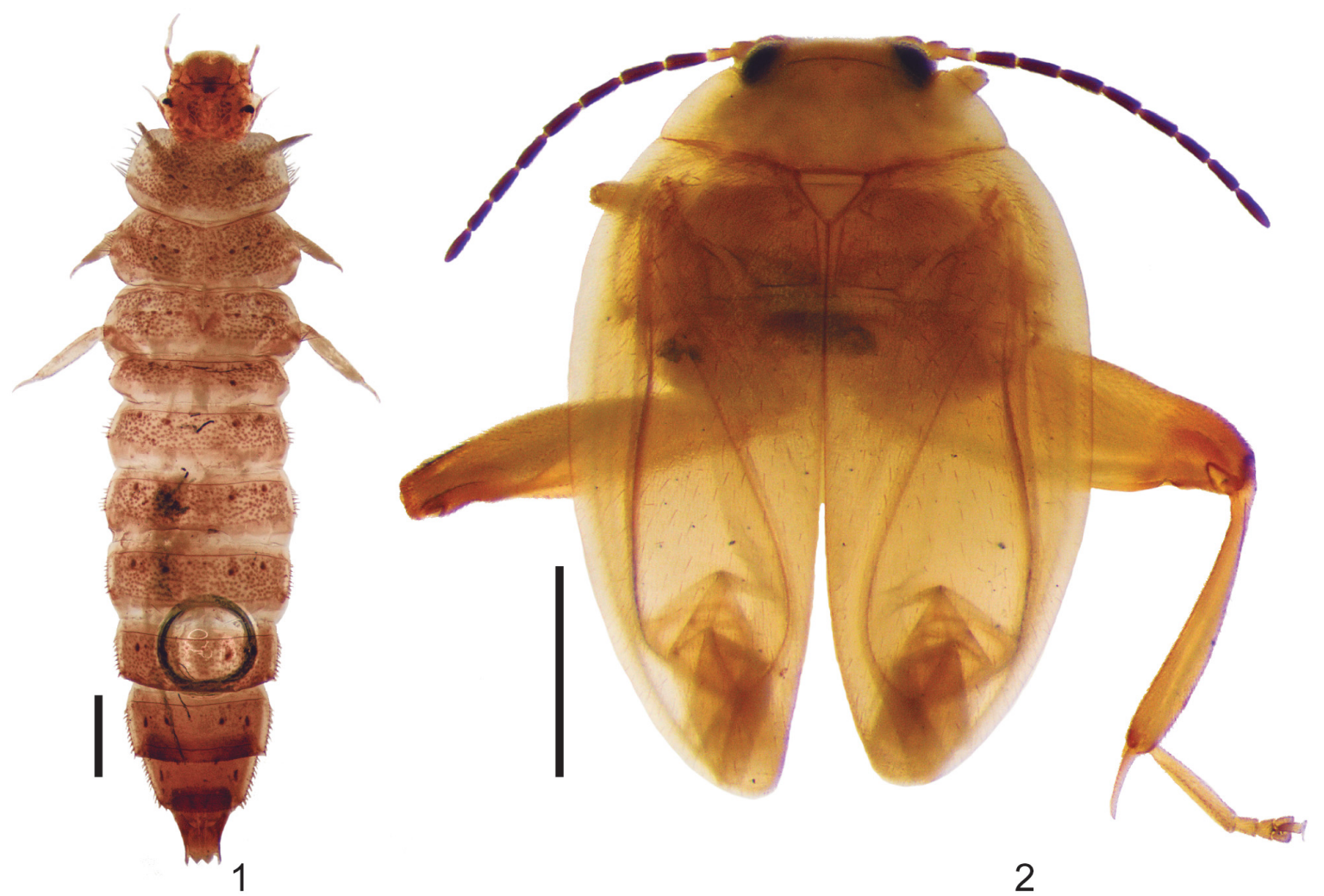

Figs 1-2. Habitus of Ora depressa (Fabricius, 1801), dorsal aspect. 1 - last instar larva. 2 - male adult. Scale bars $=1 \mathrm{~mm}$.

studied in Australia, Japan, and Argentina (WATTS 2004; Yoshitomi 2005; Libonatti 2014, 2015), the immature stages and biology of the genus are very poorly known and information concerning them may be found in only two publications. BERTRAND (1964) provided the first descriptions of the larva and the pupa for the genus, including some drawings, based on an unidentified species (Helodidae genus 2 (Ora auct.) [sic]) from Madagascar. More recently, Yoshiтomi (2005) in his revision of the Japanese scirtids presented a description and illustrations of the last instar larva of O. okinawana (Nakane, 1963), and very brief descriptions of the pupa of that species and of some early instar larvae of O. yayeyamana (M. Satô \& Chûjô, 1972), unfortunately not accompanied by illustrations.

As part of a current project which aims at studying the preimaginal morphology of Scirtidae, we studied the larval and pupal stages of Ora depressa (Fabricius, 1801) which is one of the most common species of the genus in South America. The goals of this contribution are (1) to describe and illustrate the last instar larva and the pupa of $O$. depres$s a$ including chaetotaxy of selected larval structures, (2) to compare the immature stages described herein with other members of the genus, and (3) to provide information on the biology of $O$. depressa.

\section{Material and methods}

Larvae of Ora depressa were collected using an aquatic net with a mesh size of less than $500 \mu \mathrm{m}$ and a strong round frame of $25-30 \mathrm{~cm}$ in diameter. They were kept alive and reared to adults in plastic containers $(3 \mathrm{~cm}$ in diameter, 5 $\mathrm{cm}$ in height) filled with $1-2 \mathrm{~cm}$ of mineral water and plant material from the collecting sites. Adults were identified to species level by comparing them to the redescription of the male by RUTA (2013) and a key to Argentinian species by LiBONATTI (2015).

Larvae of an unidentified species of Ora were also studied to illustrate the antennal sensorium and the maxillary digitiform sensillum of the genus: 6 larvae, ARGENTINA: Misiones Province: Iguazú National Park, 12.xii.2009, coll. M. C. Michat.

Some of the examined larvae were cleared in lactic acid (not necessary in the case of exuviae), dissected, mounted on glass slides with polyvinyl-lactoglycerol, observed, and measured under Olympus CX31 or CX41 compound microscopes equipped with an eyepiece micrometer. The remaining larvae, exuviae and pupae were submerged in several steps of household dishwashing liquid, glass cleaner, followed by sonication for 2-5 minutes, for cleaning purposes. They were dehydrated in a series of ethanol solutions in distilled water for 20 minutes each $(50 \% ; 70 \%$; $80 \% ; 96 \% \times 2 ; 100 \% \times 2$ ), then treated with a series of $100 \%$ ethanol + hexamethyldisilazane (HMDS) solutions (2:1 for 20 minutes; 1:2 for 20 minutes; pure HMDS for 30-40 minutes $\times 2$ ), gold-palladium coated, and examined and imaged using Zeiss SUPRA ${ }^{\text {тм }} 40$ scanning electron microscope.

Line-drawings were made with the aid of a drawing tube attached to Olympus CX41 compound microscope or Leica MZ6 stereoscopic microscope, except Fig. 45 which was redrawn from a SEM micrograph. Photographs were taken using Olympus LC30 or Leica DMC2900 digital cameras attached to the microscopes, and combined with Helicon Focus image stacking software. 
For larval description we follow the terminology used by HANNAPPEL \& PAULUS (1991) with the additions made by ZwICK (2008) and WATTS (2014). For pupal description we follow the terminology used by Zwick \& ZwICK (2008a).

The specimens studied herein are deposited in the collection of the laboratory of Entomology of the University of Buenos Aires.

\section{Results}

\section{Ora depressa (Fabricius, 1801)}

Material examined. ARGENTINA: Entre Ríos Province: Pre-Delta National Park: Las Piedras pond, 19-21.iii.2012, coll. M. L. Libonatti: 1 (with last instar larval and pupal exuviae), 2 of (with larval and pupal exuviae), 4 pupae (with last instar larval exuviae), 2 pupal exuviae, 3 last instar larvae, 4 early instar larvae, 4 larval exuviae. ARGENTINA: Misiones Province: Antonia Ramos Research Centre: El Tajamar pond, 18.xi.2013, coll. M. L. Libonatti: 1 (with last instar larval and pupal exuviae), 1 last instar larva.

Description. Last instar larva. Body (Fig 1) broadly elliptical; length about $11 \mathrm{~mm}$ in fully expanded specimen. Color. Body brownish testaceous; head with a relatively large elongate oval brown spot next to each frontal line and several clusters of smaller brown spots on frontale and posterior part of parietale; dorsal surface of thorax and abdomen (except uniformly brown segments 8 and 9) with many small brown spots and a transverse row of several larger brown spots in the middle of each thoracic segment and near anterior margin of each abdominal segment; ventral surface and legs testaceous.

Head (Figs 3-7). Head capsule transverse, broadly bowl-shaped, $1.8 \times$ as wide as long, with one stemma on each side behind antenna. Frontale with numerous grooved scale-like setae over whole surface and 16 other sensilla situated as follows. Anterolateral portions between the antennal socket and the frontoclypeal suture each with a transverse row of one pore-like sensillum, two short hairlike setae and one long hair-like seta. Anterior third with a transverse row of four club-like setae and two pore-like sensilla posterior to the row. Middle portion with two club-like setae. Lateral portion of each parietale with 4-5 very long hair-like setae and many spine-like setae. Dorsal surface of each parietale with numerous grooved scale-like setae on inner portion near frontal line and 14 other sensilla situated as follows. Anterolateral portion behind stemma with one short hair-like seta, one ungrooved scale-like seta, one pore-like sensillum and one club-like seta. Anterior portion at frontal line with one long hair-like seta. Middle portion at frontal line with one ungrooved scale-like seta, one pore-like sensillum, one short hair-like seta and one club-like seta. One club-like seta situated halfway between the club-like seta behind the stemma and the club-like seta at frontal line. Posterior portion with an irregular longitudinal row of four short hair-like setae. Area behind stemmata with several minute spinulae.

Antennae (Figs 8-9). Scape short, curved outwards, with several strong setae. Pedicel straight, approximately $1.5 \times$ as long as scape, with one sensorium at apex, sensorium $0.4 \times$ as long as pedicel. Flagellum broken on specimens examined.
Clypeolabrum (Figs 10-13) broadly vase-shaped, lobes well-developed, as long as wide, well-separated. Dorsal surface of each lobe with a simple, strong seta (spine of HANNAPPEL \& PAULUS 1991) situated on a small apical elevation, a pore-like sensillum in middle portion and many long hair-like setae of varying length on outer margin. Anterior portion of clypeolabrum including inner dorsal portions of lobes with a dense band of numerous, strong palisade setae, with bases almost confluent, interrupted in the middle by a bifid seta. Each side of clypeolabrum posterior to the palisade setae with an irregular oblique row of 5-6 basal setae, not clearly differentiated from smaller hair-like setae of lobes and from outer palisade setae. Rest of dorsal surface of clypeolabrum with numerous grooved scale-like setae, several short hair-like setae and two pore-like sensilla in middle portion. Frontal surface of clypeolabrum bearing, from dorsal to ventral, a pair of short hair-like setae (sensory ciliae of HANNAPPEL \& PAulus 1991), a pair of pore-like sensilla (campaniform sensilla of HannapPel \& PAUlus 1991), a transverse row of fine microtrichia and two lateral groups of three pore-like sensilla each above the cone teeth (the outermost being a depression of the cuticle; the two innermost being conical elevations of the cuticle). Ventral surface of each lobe with five inner setae, innermost the shortest. Epipharynx as described for the family (HANNAPPEL \& PAulus 1987).

Mandibles (Figs 14-16) with obtuse tip. Dorsal surface with a few short hair-like setae and numerous short microtrichia on basal portion. Ventral surface with two bristle-fields: one small, located near apex, consisting of a tuft of pectinate and branched bristles; the other larger, extended along inner margin, consisting of only branched bristles. Outer margin with a row of 16-17 long hair-like setae.

Maxillae (Figs 17-24). Galea with dense field of stalk comb-bristles. Lacinia with 7-8 teeth. Maxillary palpus elongate, four-segmented. Palpomere 1 stout, with many hair-like setae of varying length and some pore-like sensilla. Palpomere 2 slightly shorter than palpomere 1, with some very short hair-like setae, several pore-like sensilla and one long hair-like seta in about the middle of dorsal surface. Palpomere 3 the longest, slightly longer than palpomere 2; dorsal surface with a few ungrouped sensory organs; ventral surface with many sensory organs grouped in an elongate area. Palpomere $40.85 \times$ as long as palpomere 3; dorsal surface with many ungrouped sensory organs, lateral surface with one subapical digitiform sensillum; ventral surface with a few ungrouped sensory organs and three groups of sensory organs.

Labium (Figs 25-26) broadly hexagonal; posterior portion with several grooved scale-like setae and two long hair-like setae; anterior portion with several hair-like setae of varying length; lateral margins with several long hair-like setae. Labial palpus two-segmented. Palpomere 2 about $1.5 \times$ as long as palpomere 1 ; apex with one grooved conical basiconic sensillum, one elongate basiconic sensillum, three styloconic sensilla and two coeloconic sensilla.

Hypopharynx (Figs 27-31) slightly longer than wide. Stiff plate bearing a few hair-like setae on ventral surface 

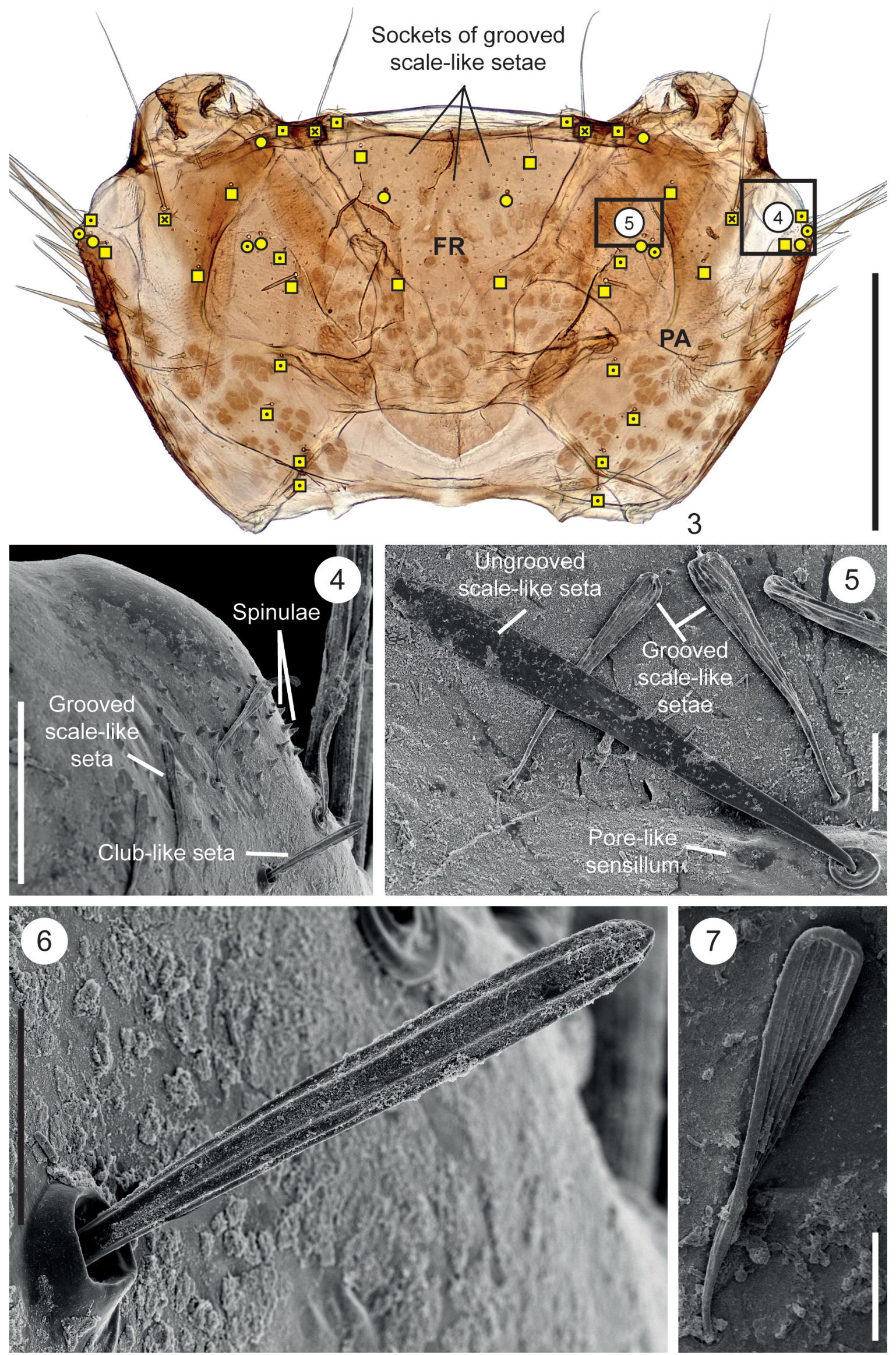

Figs 3-7. Head morphology and chaetotaxy of the last instar larva of Ora depressa (Fabricius, 1801). 3 - head capsule, dorsal aspect, showing long hair-like setae (squares with a cross), short hair-like setae (squares with dot), club-like setae (squares), ungrooved scale-like setae (circles with dot), and pore-like sensilla (circles); FR = frontale; PA = parietale. 4 - close-up of the square area indicated in figure 3.5 - close-up of the rectangular area indicated in figure 3.6 - club-like seta. 7 - grooved scale-like seta. Scale bars: $3=0.5 \mathrm{~mm} ; 4=0.05 \mathrm{~mm} ; 5-7=0.01 \mathrm{~mm}$. 


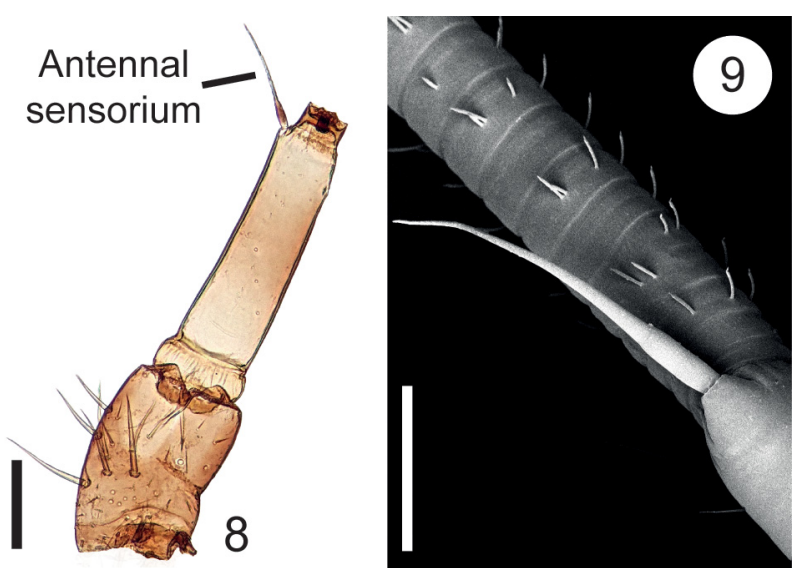

Figs 8-9. Antenna of the last instar larva of Ora species. 8-right antenna of Ora depressa (Fabricius, 1801), dorsal aspect. 9 - antennal sensorium of Ora sp. Scale bars $=0.1 \mathrm{~mm}$.

and a dense fringe of multifid setae on frontal margin. Socket and keel sclerites contiguous. Socket bristles with a very large apical tooth and 2-6 smaller teeth located on basal half of inner margin. Keel bristles with 6-10 teeth distributed along inner margin. Keel sclerite with a tran- sverse row of four pore-like sensilla situated anteriorly and a transverse row of two pore-like sensilla situated more posteriorly. Each side of hypopharynx with 5-6 comb teeth, innermost the widest, with pointed apex, remaining ones with obtuse apex. Sclerite connecting inner pair of comb teeth present, composed of two hand-like structures (each structure with 4-6 fingers). Each side of hypopharynx with a row of 24-30 long, strong, curved claw teeth; at least one outer row of numerous, very short, subtle claw teeth. Cushion area closed anteriorly, round.

Thorax (Figs 1, 32-35) widest at metanotum, almost 2× as wide as head capsule. Lateral margins each with a row of several spine-like setae and numerous long hair-like setae of variable length. Numerous grooved scale-like setae over whole dorsal surface and few short hair-like setae near anterior margin of each tergite. Pronotum with 26 other setae on each half situated in three irregular transverse rows. Anterior row with three club-like setae, three ungrooved scale-like setae and one long hair-like seta. Middle row with one long hair-like seta, seven ungrooved scale-like setae and two club-like setae. Posterior row with four ungrooved scale-like setae, one long hair-like seta and four
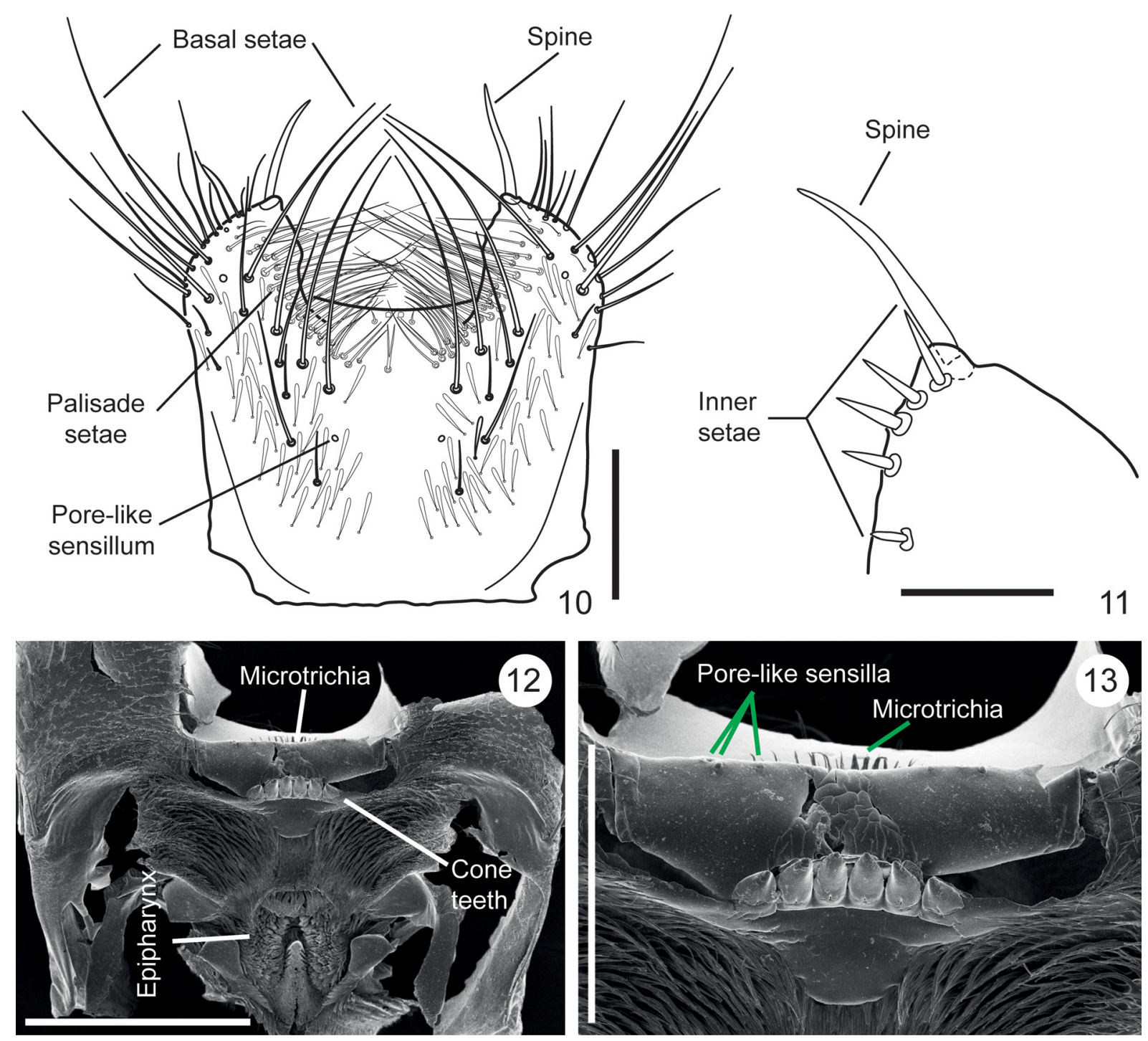

Figs 10-13. Clypeolabrum of the last instar larva of Ora depressa (Fabricius, 1801). 10 - dorsal aspect. 11 - close-up of left lobe, ventral aspect. 12 ventral aspect. 13 - close-up of frontal margin. Scale bars: $10,12=0.2 \mathrm{~mm} ; 11,13=0.1 \mathrm{~mm}$. 

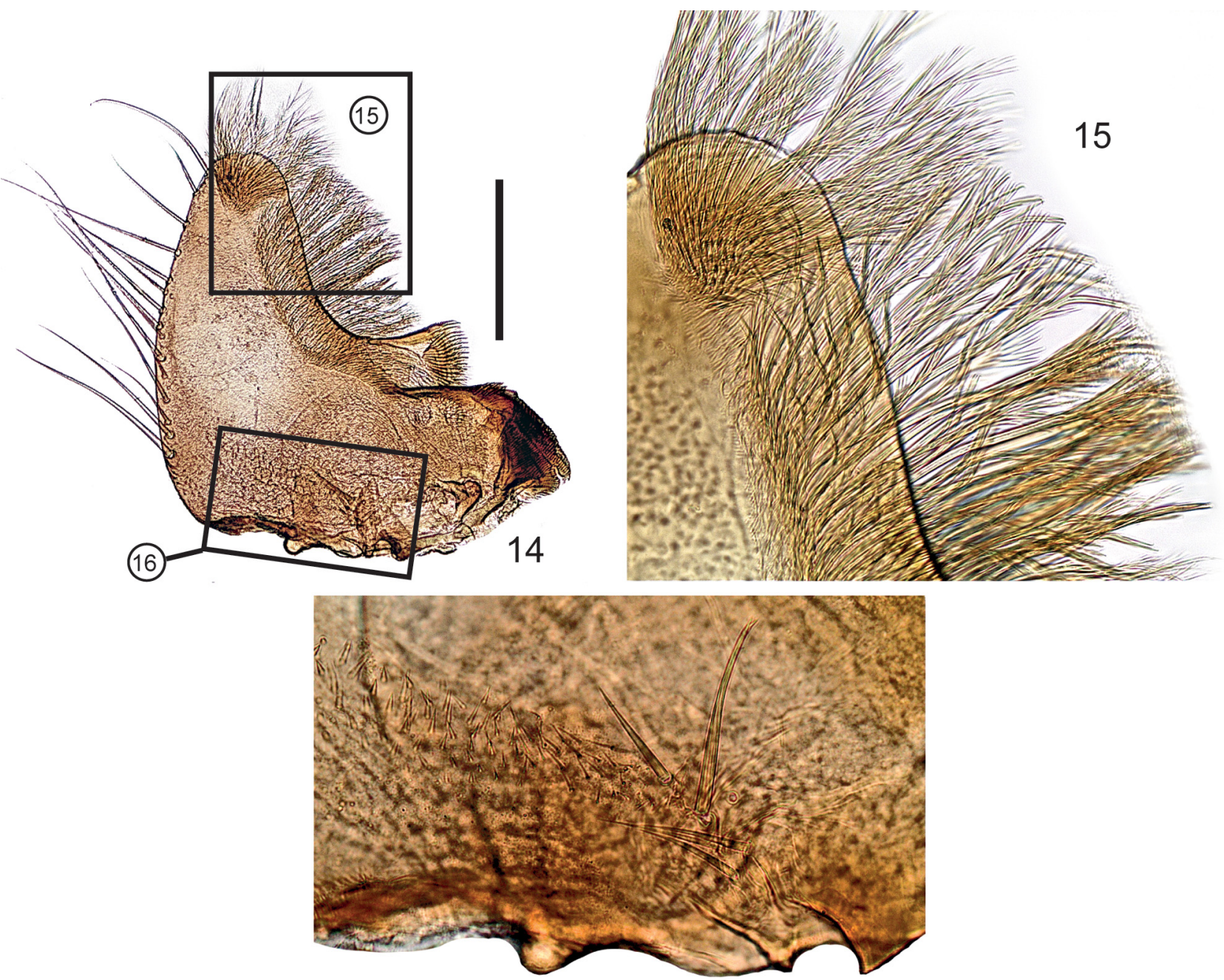

16

Figs 14-16. Mandible of the last instar larva of Ora depressa (Fabricius, 1801). 14 - ventral aspect. 15 - close-up of the rectangular area indicated in figure 14. 16 - close-up of the rectangular area indicated in figure 14 in dorsal aspect. Scale bar: $0.2 \mathrm{~mm}$.

club-like setae. Mesonotum with 20 other setae on each half situated in two irregular transverse rows. Anterior row with 11 club-like setae. Posterior row with two long hair-like setae, six ungrooved scale-like setae and one club-like seta. Metanotum with 25 other setae on each half situated in two irregular transverse rows. Anterior row with 14 club-like setae. Posterior row with eight ungrooved scale-like setae, one long hair-like seta and two club-like setae.

Legs (Figs 36-38) relatively long. Posterior surface of femur and tibiotarsus with a row of long hair-like (natatorial) setae near dorsal margin. Claw with two setae in middle, anterior seta $2 \times$ as long as posterior seta, ventral edge behind setae with a row of spinulae. Tibiotarsus of prothoracic leg with a row of pectinate setae along posterior margin; tibiotarsal organ well-developed, composed of small setae with widened feather-like distal portion.

Abdomen (Figs 1, 39-45) slightly narrower than thorax, gently tapered posteriorly. Tergites $1-7$ each with numerous grooved scale-like setae over whole surface, two irregular transverse rows of several club-like setae, a transverse row of six long hair-like setae near posterior margin, several ungrooved scale-like setae situated on posterolateral corners, and a longitudinal row of spine-like setae near each lateral margin. Posterior margin of tergites 6-7 with a transverse row of spine-like setae. Tergite 8 elongate trapezoid; posterior margin concave. Dorsal surface densely covered with grooved scale-like setae. Middle portion with an irregular transverse row consisting of two ungrooved scale-like setae and four long hair-like setae. One pair of pore-like sensilla situated halfway between the row mentioned above and the posterior margin. Posterior portion with several very short hair-like setae and two long hair-like setae. Lateral margins each with a row of 5-6 very long hair-like setae intermixed with 3-8 spine-like setae; three shorter hair-like setae situated posteriorly. Tergite 9 arch-shaped; anterodorsal margin produced medially. Anteroventral margin with simple and bifid setae, both with serrate edges. Lateral margins each with a row of several hair-like setae of variable length. Posterior margin with one long hair-like seta on each lateral corner and four minute setae between them. Sternites 1-7 each with numerous hair-like setae over whole surface, longer near lateral and posterior margins, and a longitudinal 

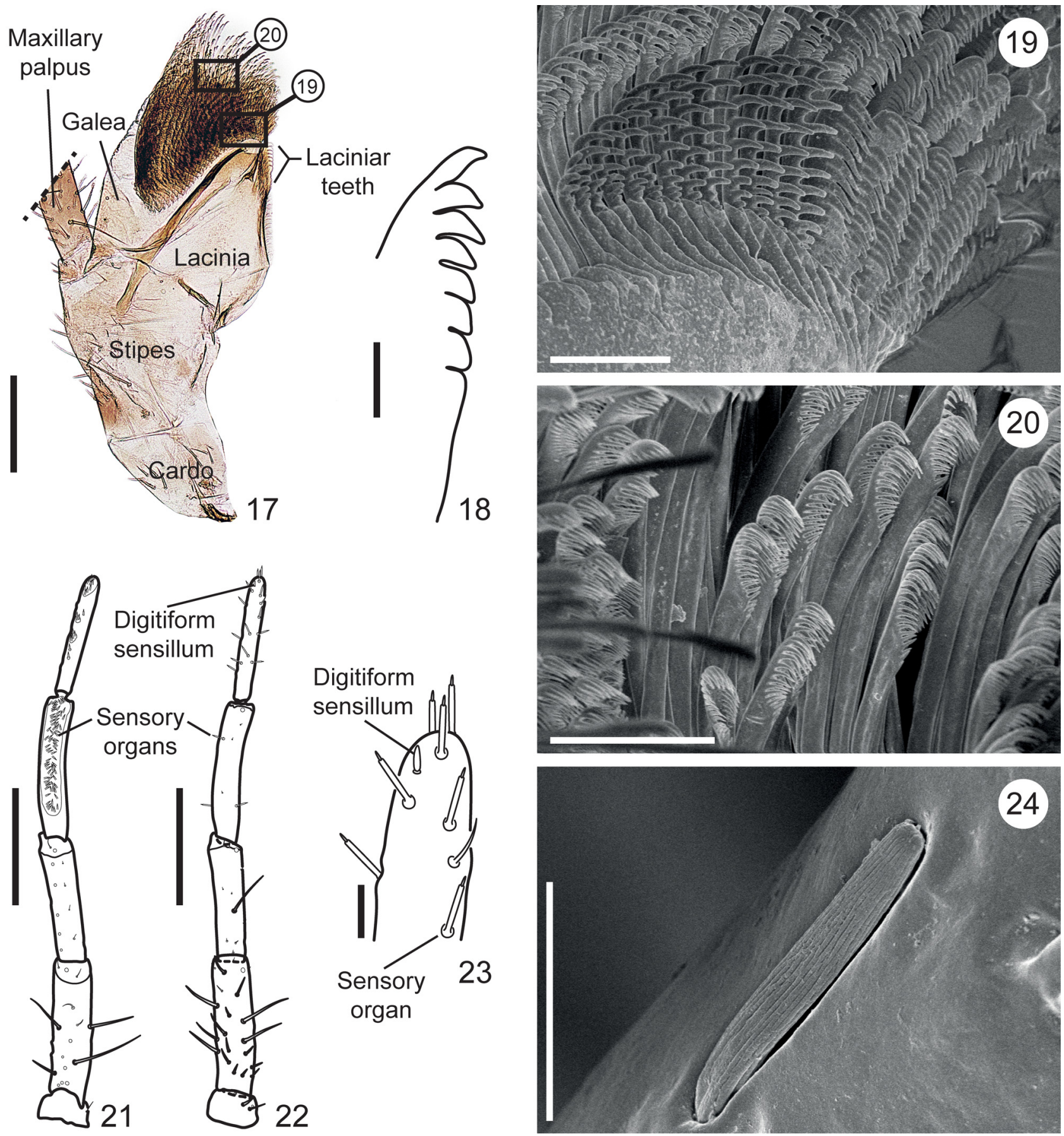

Figs 17-24. Maxilla of the last instar larva of Ora species. 17 - right maxilla of $O$. depressa (Fabricius, 1801), ventral aspect. 18 - laciniar teeth of $O$. depressa. 19 - close-up of the rectangular area indicated in figure 17, showing the stalk comb-bristles of the basal portion of galea. 20 - close-up of the rectangular area indicated in figure 17, showing the stalk comb-bristles of the apical portion of galea. 21 - right maxillary palpus of $O$. depressa, ventral aspect. 22 - right maxillary palpus of $O$. depressa, dorsolateral aspect. 23 - close-up of the apical portion of the maxillary palpus of $O$. depressa. 24 digitiform sensillum of Ora sp. Scale bars: 17, 21-22 =0.2 mm; 18-20, $23=0.02 \mathrm{~mm} ; 24=0.01 \mathrm{~mm}$.

row of spine-like setae near each lateral margin. Posterior margin of sternites 6-7 with an additional transverse row of spine-like setae. Sternite 8 wide trapezoid, densely covered with long hair-like setae. Sternite 9 semioval, middle portion with many grooved scale-like setae and several long hair-like setae, posterior margin with bipectinate setae. Five simple anal papillae.

Pupa. Body (Figs 46-48). Length about $5.5 \mathrm{~mm}$. Body brown, with several small testaceous spots on abdomen, abdominal ventrite 7 testaceous. Head, dorsal surface of thorax, elytra, and femora densely covered with long setae.

Thorax (Figs 49-50, 53-55) Pronotum lacking horns (spines of Yosнiтomi 2005), widely expanded laterally, with a row of microtrichia along each lateral margin and a dense tuft of very long pectinate setae on anterolateral corners. Anteroventral part of pterothecae with a dense tuft of very long pectinate setae, similar to that on pronotum. 

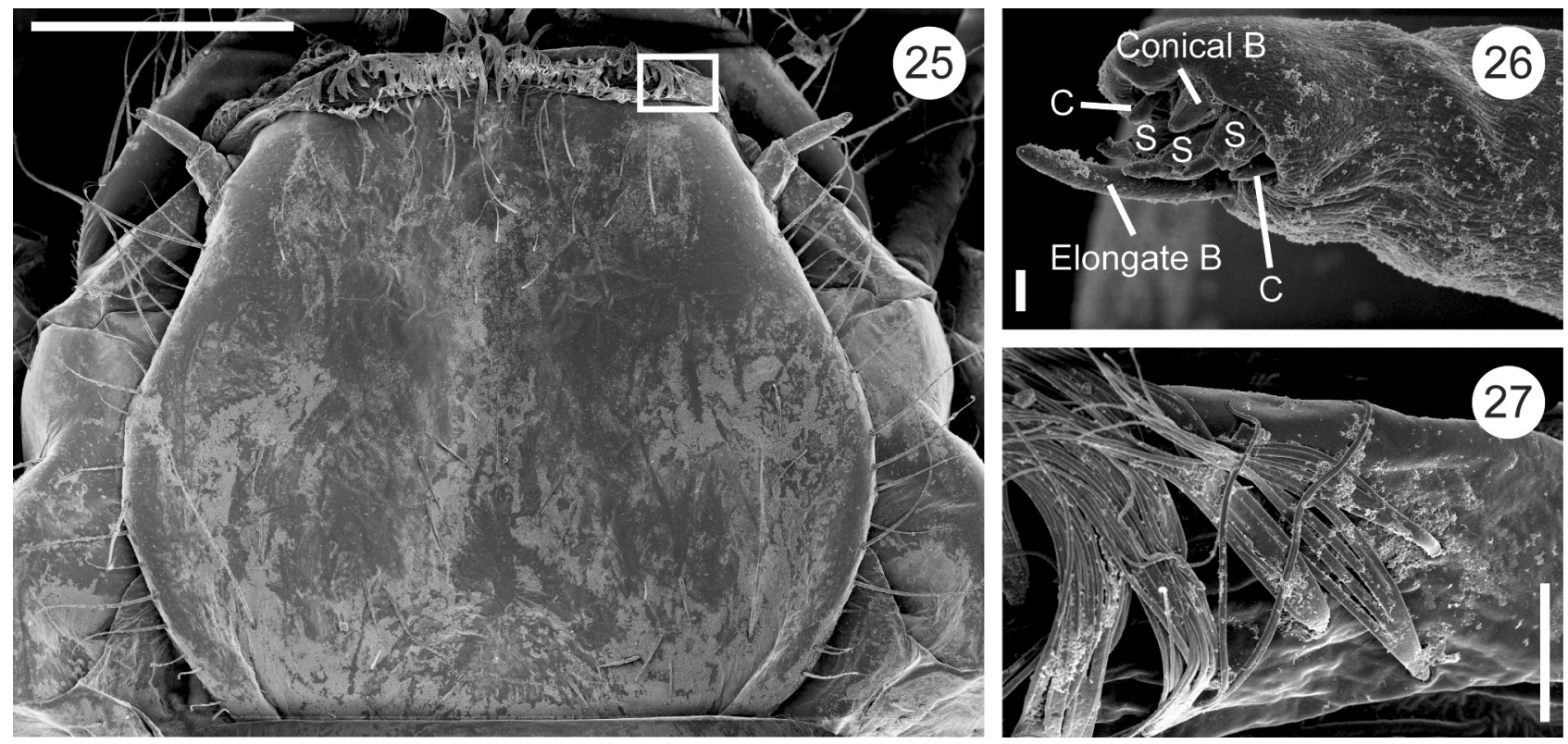

Figs 25-27. Labium of the last instar larva of Ora depressa (Fabricius, 1801). 25 - labium, ventral aspect. 26 - close-up of the apical portion of right palpus, showing conical basiconic sensillum (Conical B), elongate basiconic sensillum (Elongate B), styloconic sensilla (S), and coeloconic sensilla (C). 27 - close-up of the rectangular area indicated in figure 25 , showing the multifid setae of stiff plate (hypopharynx). Scale bars: $25=0.2 \mathrm{~mm} ; 26=$ $0.002 \mathrm{~mm} ; 27=0.01 \mathrm{~mm}$.

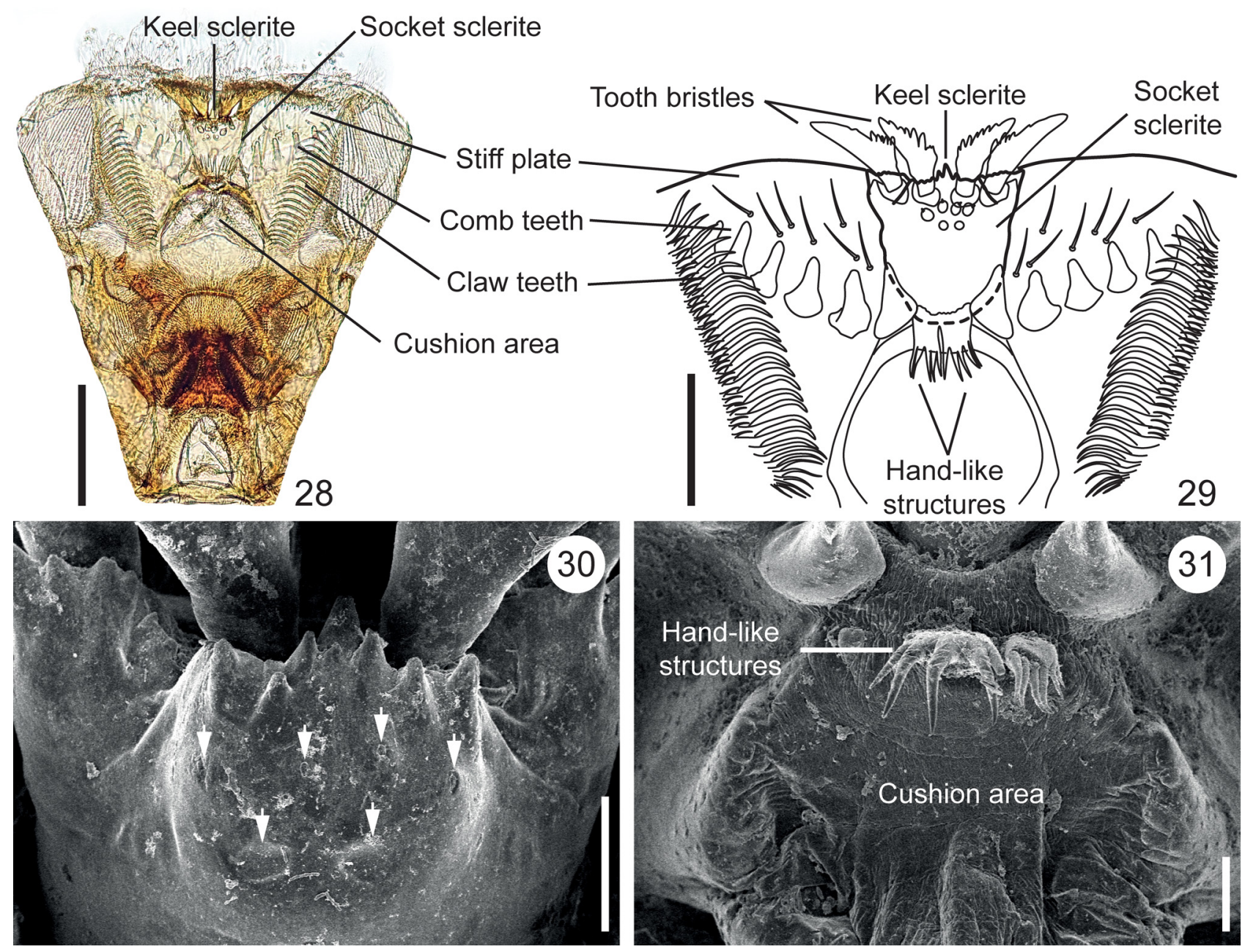

Figs 28-31. Hypopharynx of the last instar larva of Ora depressa (Fabricius, 1801). 28 - hypopharynx showing terms used in larval description. 29 close-up of anterior half of hypopharynx. 30 - close-up of keel sclerite showing six pore-like sensilla (arrows). 31 - close-up of hand-like structures and cushion area. Scale bars: $28=0.2 \mathrm{~mm} ; 29=0.1 \mathrm{~mm} ; 30-31=0.02 \mathrm{~mm}$. 


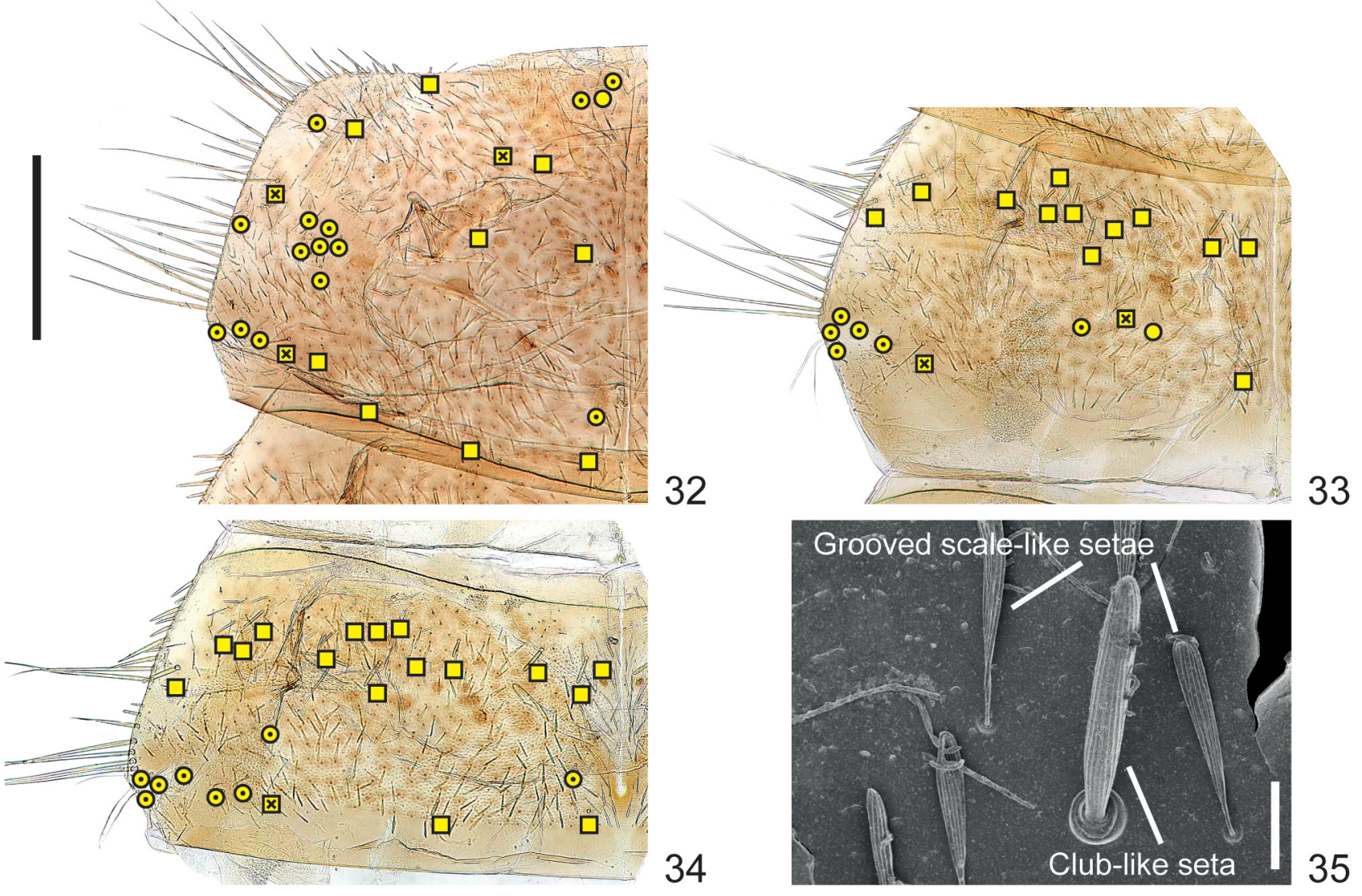

Figs 32-35. Thorax of the last instar larva of Ora depressa (Fabricius, 1801), dorsal aspect, showing long hair-like setae (squares with a cross), club-like setae (squares), ungrooved scale-like setae (circles with dot), and pore-like sensilla (circles). 32 - pronotum. 33 - mesonotum. 34 - metanotum. 35 close-up of several grooved scale-like setae and one club-like seta of thorax. Scale bars: $32-34=0.5 \mathrm{~mm} ; 35=0.02 \mathrm{~mm}$.

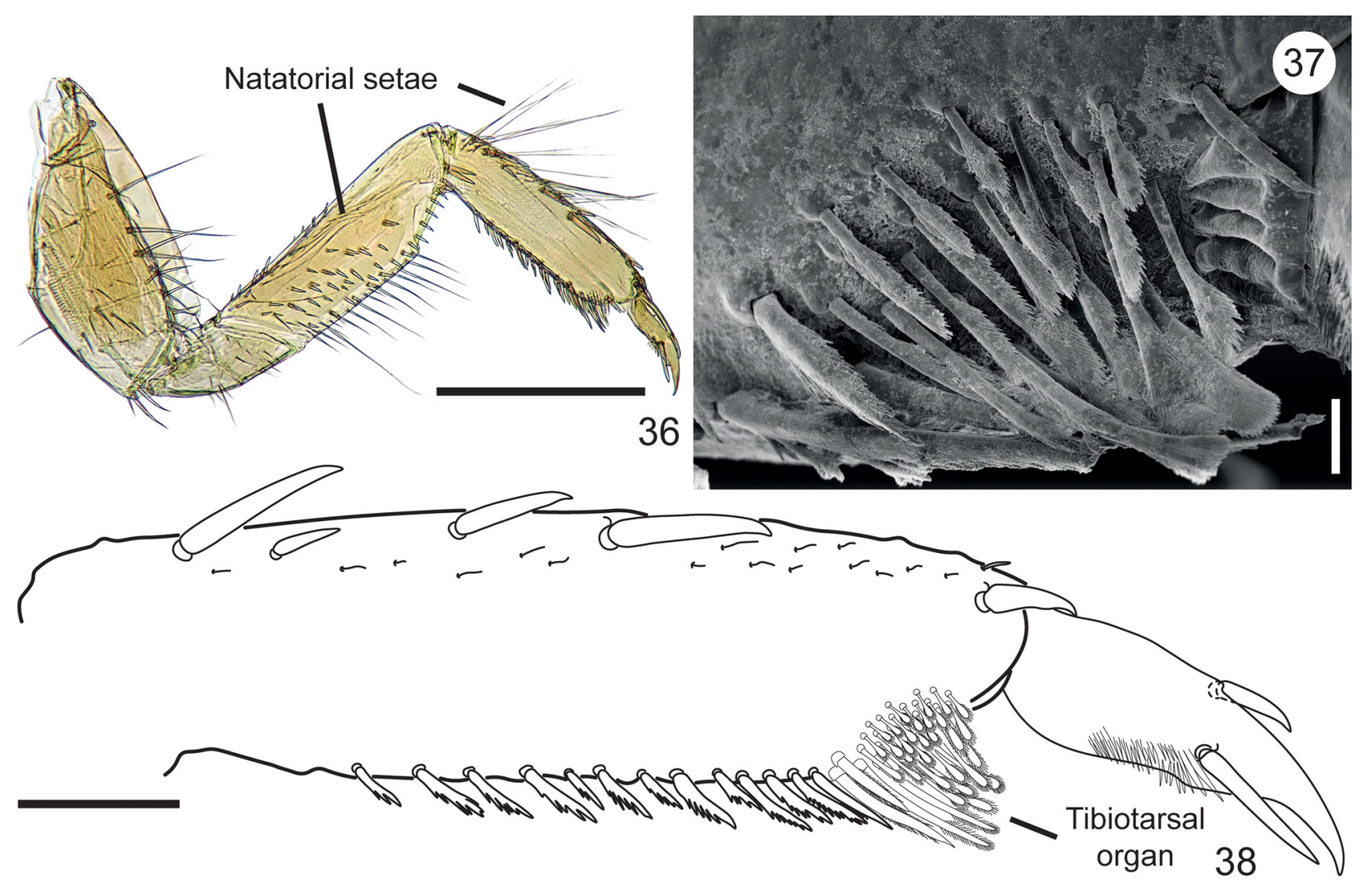

Figs 36-38. Leg of the last instar larva of Ora depressa (Fabricius, 1801). 36 - prothoracic leg. 37 - tibiotarsus and pretarsus of prothoracic leg. 38 close-up of tibiotarsal organ. Scale bars: $36=0.5 \mathrm{~mm} ; 37=0.1 \mathrm{~mm} ; 38=0.01 \mathrm{~mm}$. 

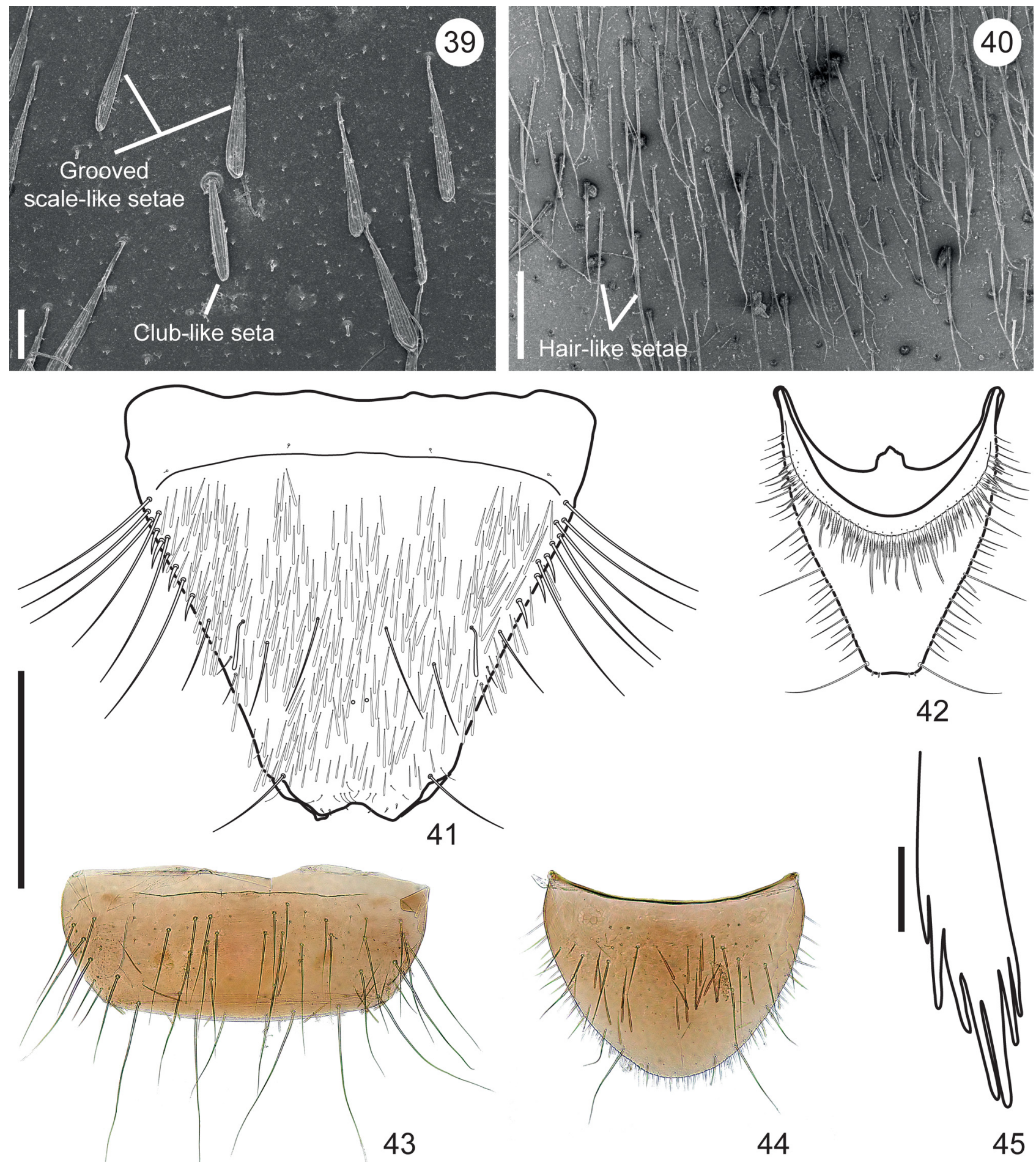

Figs 39-45. Abdomen of the last instar larva of Ora depressa (Fabricius, 1801). 39 - close-up of the chaetotaxy of tergites 1-7. 40 - close-up of the chaetotaxy of sternites $1-7.41$ - tergite 8 , dorsal aspect. 42 - tergite 9 , ventral aspect. 43 - sternite 8 , ventral aspect. 44 - sternite 9 , ventral aspect. 45 - marginal seta of sternite 9 . Scale bars: $39=0.02 \mathrm{~mm} ; 40=0.1 \mathrm{~mm} ; 41-44=0.5 \mathrm{~mm} ; 45=0.003 \mathrm{~mm}$.

The row of microtrichia together with both dense tufts of setae form an hydrophobic setation that covers the edges of the lateral pronotal expansions (Fig. 53).

Abdomen (Figs 51-52, 56-58). Ventrites 1-6 with an irregular transverse row of long setae on dorsal surface, an irregular transverse row of long setae on ventral surface, and a longitudinal row of long setae along lateral margins. Ventrite 7 without setae. Sexual dimorphism present: male attachment organ consisting of a square base and a pair of processes each with pointed apex, covered with short teeth; female attachment organ consisting of a triangular base, a pair of processes each with widened apex, covered with longer teeth, and an additional small rounded process situated basally between the pair of processes.

Biology. Larvae were collected from a flooded area adjacent to Las Piedras pond (Pre-Delta National Park, Entre Ríos Province), mainly dominated by the plant species Polygonum punctatum Elliott, 1817 and Thalia geniculata 

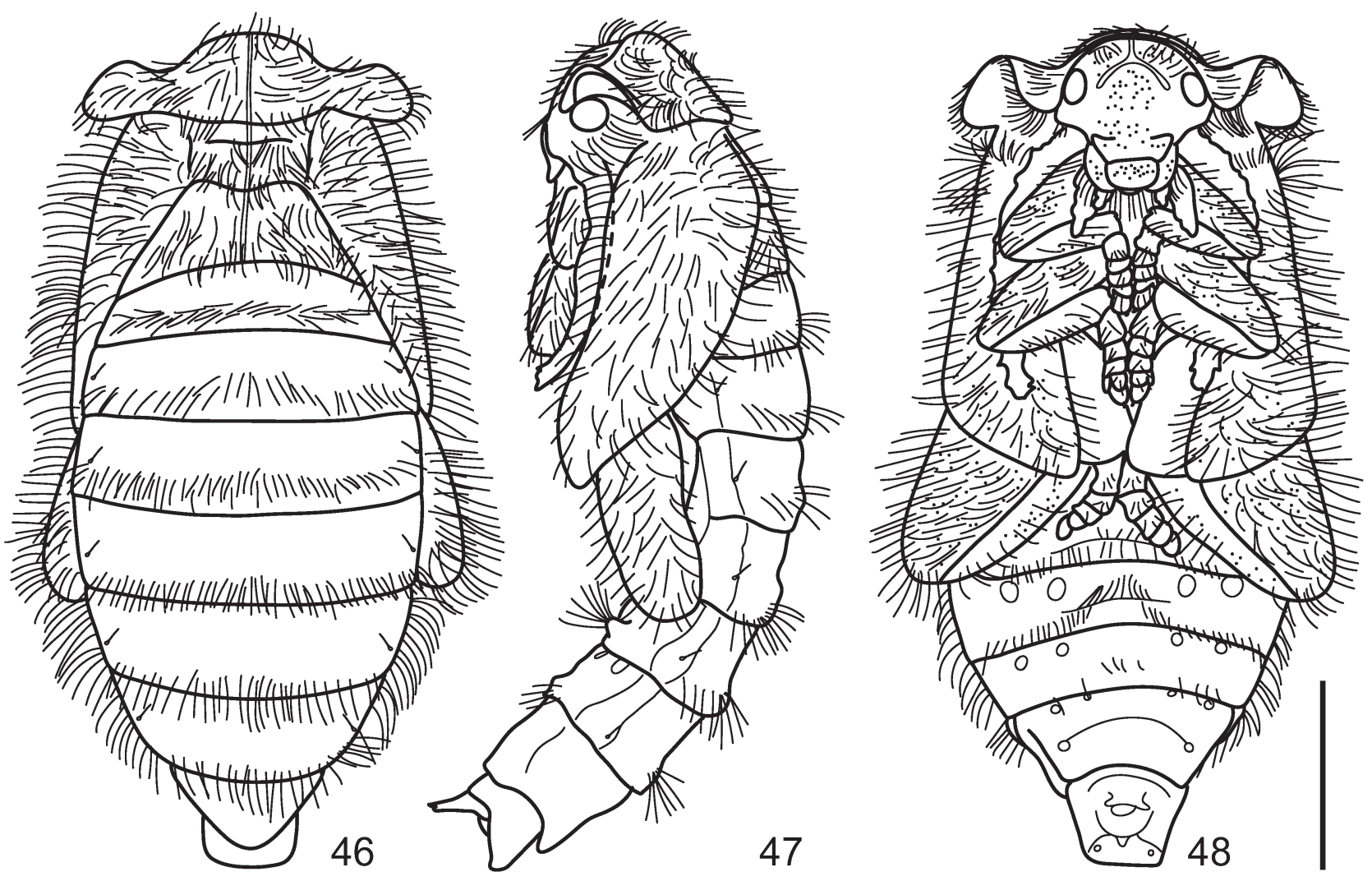

Figs. 46-48. Habitus of the pupa of Ora depressa (Fabricius, 1801). 46 - dorsal aspect. $47-$ lateral aspect. $48-$ ventral aspect. Scale bar $=1.0$ mm.

Linnaeus, 1753 (Fig. 69), and from marginal areas of El Tajamar pond (CIAR, Misiones Province), dominated by Juncaceae and Poaceae. Both ponds are natural and exposed to sun. Several exuviae of pupae were also found in the field. The rearing of the larvae allowed us to observe that pupae are aquatic; they hang from the water's surface. The exuviae of the last instar larva remains attached to the pupa during pupation. Pupae make abdominal movements when disturbed. Pupal period is one day under laboratory conditions. Adults emerge in the evening or night.

\section{Discussion}

As previously mentioned, immature stages of the scirtid genus Ora are very poorly known. The only treatments of members of the genus are those dealing with an African species named 'Helodidae genus 2' (BERTRAND 1964) and two Japanese species, O. okinawana and O. yayeyamana (Yoshitomi 2005).

The last instar larva of $O$. depressa exhibits the characters traditionally recognized as diagnostic of the genus by previous authors (BERTRAND 1964, Yoshitomi 2005): tip of mandible obtuse (Fig. 14) and fourth maxillary palpomere long, almost as long as third palpomere (Fig. 21). From the comparison of the larva of $O$. depressa with those of 'Helodidae genus 2' and O. okinawana (BERTRAND 1964, Yosнiтомі 2005), we found the following differences: the lobes of the clypeolabrum are as long as wide in $O$. depres$s a(2 \times$ as long as wide in the other species); and the socket bristles bear 2-6 inner teeth in $O$. depressa (one tooth in the other species) (Bertrand 1964, Yoshitomi 2005). Ora depress $a$ and 'Helodidae genus 2' are further distinguished from each other by: the thorax which is almost $2 \times$ as wide as the head capsule in $O$. depressa and slightly wider than the head capsule in 'Helodidae genus 2'; and the pedicel which is $1.5 \times$ as long as the scape in $O$. depressa and as long as the scape in 'Helodidae genus 2'.

Ora depress $a$ and $O$. okinawana also differ in: the number of field bristles on the ventral surface of the mandible which is two in $O$. depressa and one in O. okinawana; the third maxillary palpomere which is $6.5 \times$ as long as wide in O. depressa and $3.0 \times$ as long as wide in O. okinawana; the fourth maxillary palpomere which is $0.85 \times$ as long as the third palpomere in $O$. depress $a$ and $1.25 \times$ as long as the third palpomere in O. okinawana; the number of comb teeth of the hypopharynx which is 5-6 pairs in O. depressa and seven pairs in O. okinawana; the tergite 8 which narrows much more apically and exhibits longer lateral setae in $O$. depressa than in O. okinawana; the sternite 8 which is approximately $2.3 \times$ as wide as long in $O$. depressa and approximately $1.7 \times$ as wide as long in O. okinawana; the anterodorsal margin of the tergite 9 which is produced medially in $O$. depress $a$ and is uniformly concave, lacking a median process, in O. okinawana; the presence of bifid setae on the anteroventral margin of the tergite 9 in $O$. depressa which are absent in O. okinawana; the two apical setae of tergite 9 which are closer to each other in $O$. depressa than in O. okinawana; and the sternite 9 which is $1.5 \times$ as wide as long in $O$. depressa and almost $2 \times$ as wide as long in $O$. okinawana. The short description of $O$. yayeyamana presented by Yоsнітомі (2005) is based on early instar larvae and not accompanied by illustrations, 
and only one difference could be found: the pedicel is as long as the scape in this species and longer than the scape in O. depressa.

One remarkable difference between $O$. depressa and the other species is the habitat where they develop. Ora depressa inhabits ponds exposed to sun while the other species mainly inhabit phytotelmata (tree holes and
Pandanus Parkinson, 1773 in the forest) and sometimes puddles and small ponds in forests (BERTRAND 1964, Yoshitomi 2005).

The presence of scale-like setae has never been reported for any known scirtid species apart from $O$. depressa. Setae apparently very similar to the ungrooved scale-like setae of $O$. depressa have been found in the larvae of other aquatic
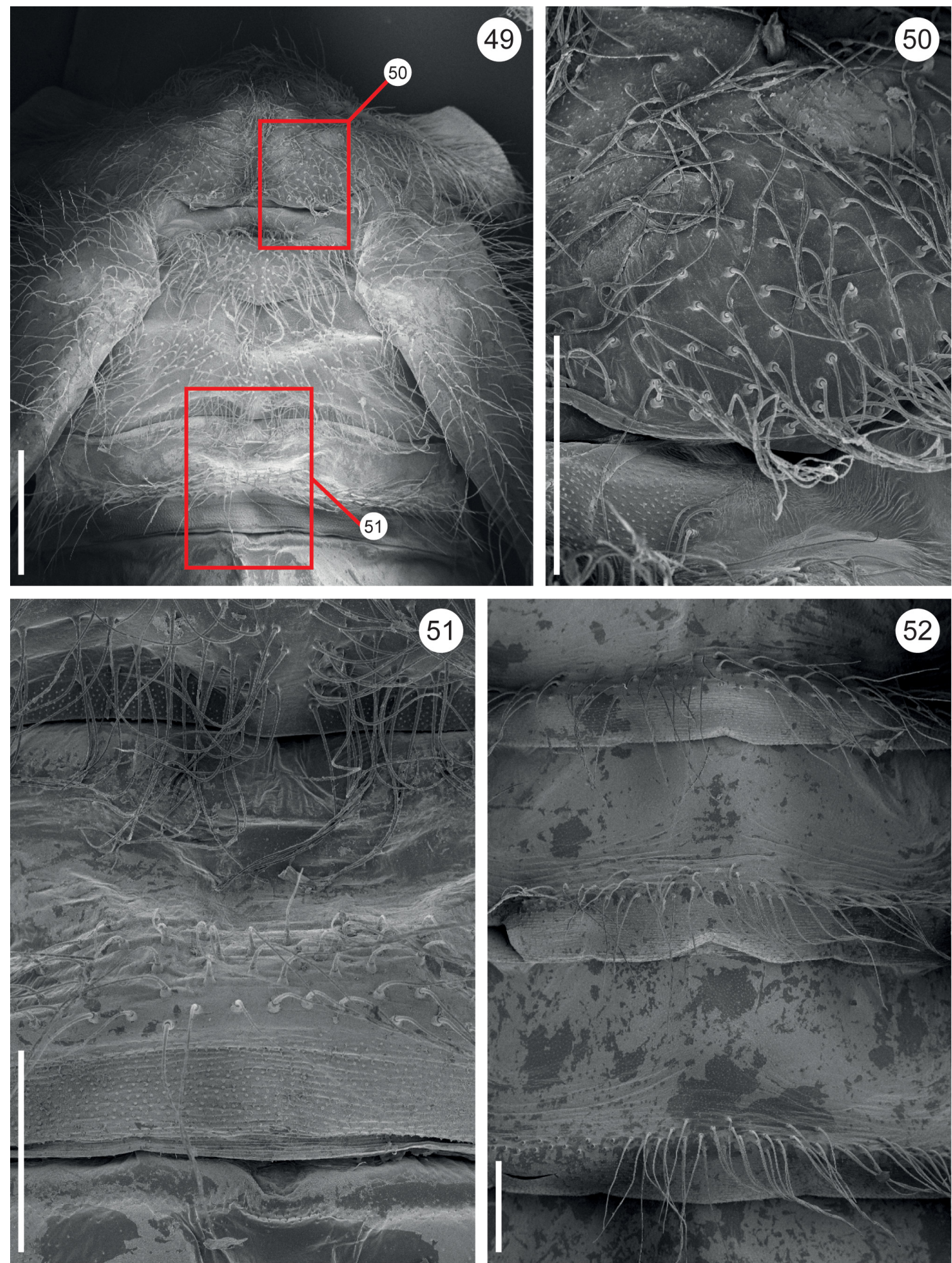

Figs 49-52. Pupa of Ora depressa (Fabricius, 1801), dorsal aspect. 49 - thorax. 50-51 - close-ups of the rectangular area indicated in figure 49. $52-$ close-up of abdomen. Scale bars: $49=0.5 \mathrm{~mm} ; 50-52=0.2 \mathrm{~mm}$. 
Coleoptera, such as Dytiscidae (Michat 2008), Hydrophilidae (MinOSHIMA \& HAYASH 2011) and Epimetopidae (FIKÁČEK et al. 2011). On the other hand, the club-like setae of $O$. depressa resemble those defined as chemoreceptors in Elodes Latreille, 1796 and Odeles Klausnitzer, 2004 by Hannappel \& Paulus (1987); both types of setae are short, stout, and their surface is grooved, but the apical pronounced pore present in Elodes and Odeles was not evident in $O$. depressa under SEM observations. Besides, the club-like setae of $O$. depressa are apparently similar to the 'short stout setae' present over the dorsal surface of the thorax and the abdomen of $O$. okinawana described by Yosнiтомi (2005) and the 'peg-like setae' present over the dorsal surface of the body of some Australian species of the genera Contacyphon Gozis, 1886, Nothocyphon Zwick, 2015 and Scirtes Illiger, 1807 described by WATTS (2014). However, detailed descriptions or SEM images of these setae are lacking.
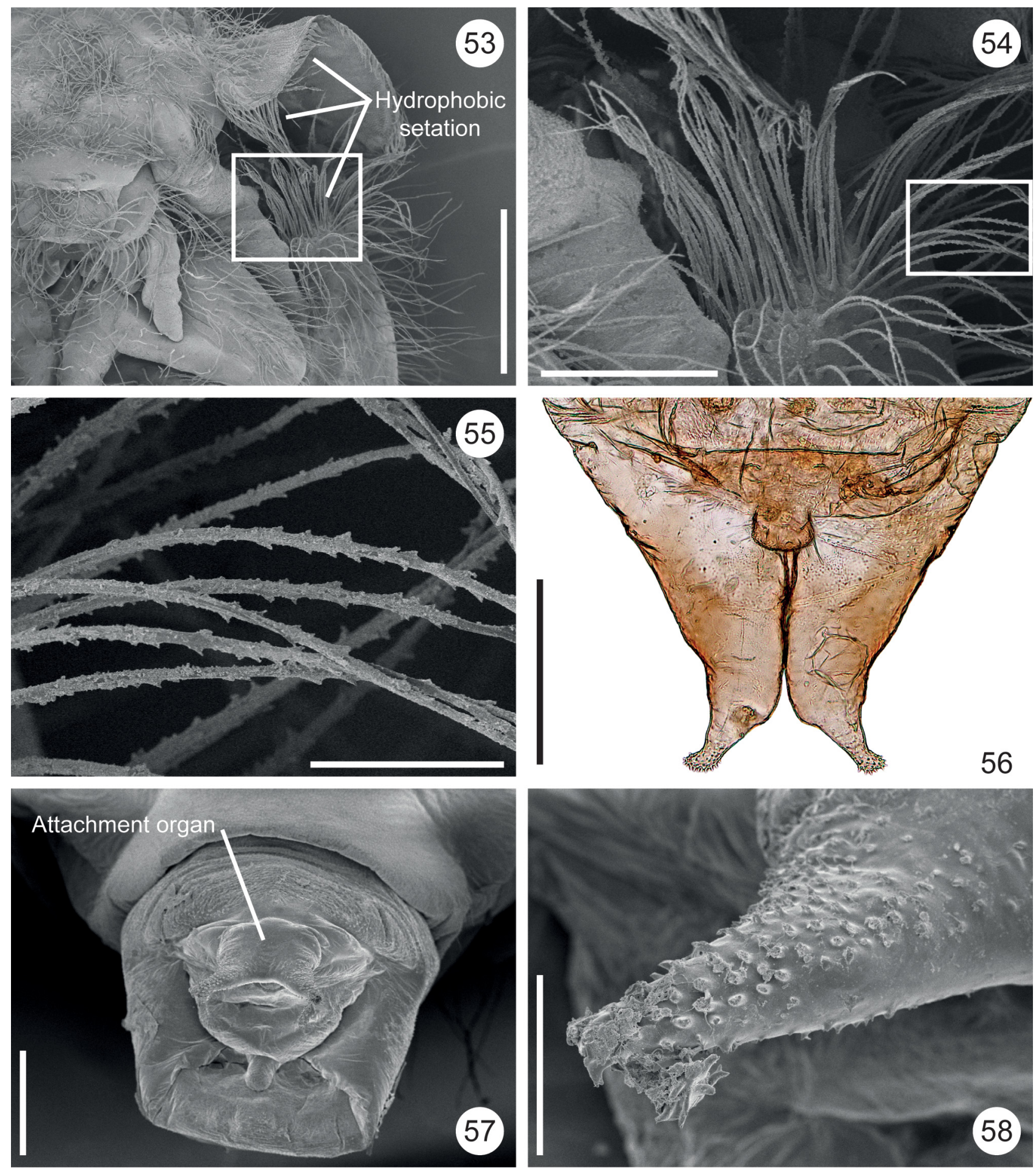

Figs 53-58. Pupa of Ora depressa (Fabricius, 1801), ventral aspect. 53 - left side of head and prothorax. 54 - close-up of the rectangular area indicated in figure 53.55 - close-up of the rectangular area indicated in figure 54.56 - female attachment organ. 57 - terminal portion of the abdomen of male. 58 - close-up of male attachment organ. Scale bars: $53=0.5 \mathrm{~mm} ; 54,56-57=0.2 \mathrm{~mm} ; 55,58=0.05 \mathrm{~mm}$. 
The presence of long, seemingly natatorial setae on the legs of $O$. depressa larvae is noteworthy. Among Scirtidae, this feature is only shared with the undetermined Ethiopian larvae described by BERTRAND (1964) as 'Helodidae genus 1', 'Helodidae genus 2', 'Helodidae genus 3', and 'Helodidae genus 9'. According to BerTRAnd (1972) many larvae living in standing waters are characterized by the presence of swimming hairs whereas those living in running waters show a peculiar development of spine-like setae on the legs and body.

Both descriptions given by BERTRAND (1964) and YoSHIтомі (2005) for the pupae of 'Helodidae genus 2'and O. okinawana, respectively, are short and include no illustrations, but still a couple of differences could be found: the pronotum of $O$. depressa lacks horns (one anterior pair present in 'Helodidae genus 2' and two pairs (one anterior and one posterior) in O. okinawana), and the place where pupation occurs which is underwater in O. depressa, while being out of the water and under fallen leaves in the other species. Underwater pupation evolved independently several times within Scirtidae, being also present in the genera Scirtes and Hydrocyphon Redtenbacher, 1858. Pupae of the European species Scirtes haemisphaericus (Linnaeus, 1758) are firmly attached to leaves of Spirodela Schleiden, 1839 or roots of Juncus Linnaeus, 1753 and breathe the oxygen from the aerenchym of these plants (ZwICK \& ZwICK 2008a). Those of the American species Scirtes tibialis Guérin-Méneville, 1843 and the Australian species $S$. auratus Watts, 2004 apparently also exploit the intercellular air supply of plants (KRAATZ 1918, ZwICK \& ZwICK 2008a, WATTS 2014). Hydrocyphon pupates under submerged stones and uses a plastron to breathe (KLAusNITZER 2009). The pupa of $O$. depressa and the other known aquatic pupae share the absence of pronotal horns. In contrast to the other known aquatic pupae, however, that of $O$. depressa floats freely at the surface of water and breathes atmospheric oxygen with a pair of snorkels formed by lateral pronotal extensions surrounded by hydrophobic setation (Fig. 53).

The genus Ora has been postulated to be sister to Scirtes based on morphological evidence from adults and larvae (Yoshitomi 2005) and adults only (LAWrence \& Yoshitomi 2007). Indeed, molecular evidence supports a monophyletic origin of Ora, Scirtes and Exochomoscirtes Pic, 1916 (CoOper et al. 2014). We found that $O$. depressa shares with these genera several larval character states defined by previous authors (HANNAPPEL \& PAUlus 1987; Yoshitomi 2005; Zwick 2008, 2011; WatTs 2014): three pore-like sensilla on each side of the frontal surface of clypeolabrum (character state unkown for Exochomoscirtes); basal pair of pore-like sensilla of keel sclerite situated in a transverse row; presence of a sclerite with a pair of processes in middle of the inner pair of comb teeth; and setae of tibiotarsal organ with widened, feather-like distal portions.

In this contribution we provided the first description of the immatures of a New World member of Ora, and report for the first time an aquatic pupa for the genus which is fully described and illustrated. From our results, several larval characters related to morphology, morphometry and chaetotaxy are useful to distinguish species. Preliminary research indicates that scale-like setae on dorsal surface of body and natatorial setae on legs are also present in other South American species of Ora (Libonatti, unpubl. data). Studies of the larvae and pupae of other members of the genus, including the type species $O$. trobertii (Guérin-Méneville, 1861), would be very interesting to define in more detail the diagnosis of Ora based on larval and pupal characters and, in the future, test its monophyly.

\section{Acknowledgements}

Special thanks to Georgina Rodriguez for her valuable assistance in the preparation of the material for SEM and valuable discussions on aquatic insect sensilla. We also thank two anonymous reviewers and Martin Fikáček for their comments and corrections of the manuscript. We are thankful to the National Parks Administration of Argentina and the Antonia Ramos Research Centre for giving as permission to collect the material used in this research. This project was supported in part by grants PICT-20140853 (ANPCyT) and UBACyT-20020150100170BA (UBA). Field and laboratory work by M. L. Libonatti was also partly supported by a postdoctoral fellowship from CONICET.

\section{References}

BEERBOWER F. V. 1943: Life history of Scirtes orbiculatus Fabricius (Coleoptera: Helodidae). Annals of the Entomological Society of America 36: 672-680.

BEIER M. 1949: Koerperbau und Lebensweise der Larve von Helodes hausmanni Gredler (Col. Helodidae). Eos 25: 49-100.

BERTRAND H.1964: Contribution a l'étude des premiers états des Coléoptères aquatiques de la région éthiopienne. (6e note) Familie: Helodidae. Bulletin de l'Institut Fondamental d'Afrique Noire 26: 513-579.

BERTRAND H. 1972: Larves et nymphes des Coléoptères aquatiques $d u$ Globe. F. Paillart, Paris, 804 pp.

COOPERS. J. B., WATTS C. H. S., SAINT K. M. \& LEIJS R. 2014: Phylogenetic relationships of Australian Scirtidae (Coleoptera) based on mitochondrial and nuclear sequences. Invertebrate Systematics 28: $628-642$

FIKÁČEK M., BARCLAY M. V. L. \& PERKINS P. D. 2011: Two new species of the Epimetopus mendeli species group and notes on its adult and larval morphology (Coleoptera: Hydrophiloidea: Epimetopidae). Acta Entomologica Musei Nationalis Pragae 51: 477-504.

FRIEDENREICH C. W. 1883: Pentameria bromeliarum, eine pentamere Halticide. Entomologische Zeitung 44: 140-144.

GOOD H. G. 1924: Notes on the life history of Prionocyphon limbatus Lec. (Helodidae, Coleoptera). Journal of the New York Entomological Society 32: 79-84.

HANNAPPEL U. \& PAULUS H. F.1987: Arbeiten zu einem phylogenetischen System der Helodidae (Coleoptera) - Feinstrukturuntersuchungen an europäischen Larven. Zoologische Beiträge (N. F.) 31: 77-150.

HANNAPPEL U. \& PAULUS H. F. 1991: Some undetermined Helodidae larvae from Australia and New Zealand: fine structure of mouthparts and phylogenetic position. Pp. 89-128. In: ZUNINO M., BELLÉS X. \& BLAS M. (eds.): Advances in Coleopterology. Asociacion Europea de Coleopterología, Barcelona, 323 pp.

HANNAPPEL U. \& PAULUS H. F. 1997: Larvenkenntnis und Verbreitung der Scirtidae in der westlichen Paläarktis mit einem Bestimmungsschlüssel europäischer Larven der Gattung Elodes Latreille, 1796 (Coleoptera, Scirtidae). Koleopterologische Rundschau 67: $225-251$. 
HUDSON G. V. 1934: New Zealand beetles and their larvae: an elementary introduction to the study of our native Coleoptera. Ferguson \& Osborne, Wellington, $236 \mathrm{pp}$.

KITCHING R. L. \& ALLSOPP P. G. 1987: Prionocyphon niger sp. n. (Coleoptera: Scirtidae) from water-filled tree holes in Australia. Journal of the Australian Entomological Society 26: 73-79.

KLAUSNITZER B. 2009: Insecta: Coleoptera: Scirtidae. Süßwasserfauna von Mitteleuropa. Bd. 20/17. Spektrum Akademischer Verlag, Heidelberg, 326 pp.

KRAATZ W. C. 1918: Scirtes tibialis Guerin (Coleoptera: Helodidae), with observations on its life history. Annals of the Entomological Society of America 11: 393-400, pl. 35.

LAWRENCE J. F. \& YOSHITOMI H. 2007: Nipponocyphon, a new genus of Japanese Scirtidae (Coleoptera) and its phylogenetic significance. Elytra 35(2): 507-527.

LIBONATTI M. L. 2014: A revision of the genus Ora Clark, 1865 (Coleoptera: Scirtidae) in Argentina (part I) - descriptions of new species. Zootaxa 3884: 27-44.

LIBONATTI M. L. 2015: A revision of the genus Ora Clark, 1865 (Coleoptera: Scirtidae) in Argentina (part II) -redescriptions, updated distributions and a key to species. Zootaxa 3985: 69-97.

LIBONATTI M. L. \& RUTA R. 2018: Chapter 15.7 Family Scirtidae. Pp. 599-603. In: HAMADA N., THORP J. \& ROGERS D. C. (eds.): Thorp and Covich's Freshwater Invertebrates, Fourth Edition: Keys to Neotropical Hexapoda, Volume Three. Elsevier, San Diego, 836 pp.

MICHAT M. C. 2008: Description of the larvae of three species of Laccophilus Leach and comments on the phylogenetic relationships of the Laccophilinae (Coleoptera: Dytiscidae). Zootaxa 1922: 47-61.

MINOSHIMAY. \& HAYASHI M. 2011: Larval morphology of the Japanese species of the tribes Acidocerini, Hydrobiusini and Hydrophilini (Coleoptera: Hydrophilidae). Acta Entomologica Musei Nationalis Pragae 51(supplementum): 1-118.

OSTEN-SACKEN C. R. 1862: Descriptions of some larvae of North American Coleoptera. Proceedings of the Entomological Society of Philadelphia 1: 105-130.

PICADO C. 1913: Les broméliacées épiphytes considerées comme milieu biologique. Bulletin des Sciences de la France et de la Belgique 47: 215-360.

RUTA R. 2013: Review of Scirtidae (Coleoptera: Scirtoidea) described by Johan Christian Fabricius (1745-1808). Zootaxa 3646(1): 51-67.

RUTA R. \& YOSHITOMI H. 2010: Revision of the genus Exochomoscirtes Pic (Coleoptera: Scirtidae: Scirtinae). Zootaxa 2598: 1-80.
STRIBLING J. B. \& YOUNG D. K. 1990: Descriptions of the larva and pupa of Flavohelodes thoracica (Guerin-Meneville) with notes on a phytohelma association (Coleoptera: Scirtidae). Proceedings of the Entomological Society of Washington 92(4): 765-770.

WATTS C. H. S. 2004: Revision of Australian Scirtes Illiger and Ora Clark (Coleoptera: Scirtidae). Transactions of the Royal Society of South Australia 128(2): 131-167.

WATTS C. H. S. 2014: The larvae of some Australian Scirtidae (Coleoptera) with a key to known genera. Transactions of the Royal Society of South Australia 138(1): 1-91.

YOSHITOMI H. 1997: A revision of the Japanese species of the genera Elodes and Sacodes (Coleoptera, Scirtidae). Elytra 25(2): 349-417.

YOSHITOMI H. 2001: Taxonomic study on the genus Hydrocyphon (Coleoptera, Scirtidae) of Japan and her adjacent regions. Elytra 29(1): 87-107.

YOSHITOMI H. 2005: Systematic revision of the family Scirtidae of Japan, with phylogeny, morphology and bionomics (Insecta: Coleoptera, Scirtoidea). Japanese Journal of Systematic Entomology Monographs Series 3:1-212.

YOSHITOMI H. 2012: Oriental Hydrocyphon (Coleoptera: Scirtidae: Scirtinae): seven new species from Indonesia, Thailand, Malaysia, and India. Psyche 2012: 1-16.

ZWICK P. 2007: Elodes tricuspis: description of the larva, and notes on biology (Coleoptera: Scirtidae). Lauterbornia 59: 85-93.

ZWICK P. 2008: Das Tibiotarsalorgan, ein neues Merkmal larvaler Scirtidae (Coleoptera). Entomologische Nachrichten und Berichte 52: $51-54$.

ZWICK P. \& HECHT M. 2008: Life history and instar number of Elodes minuta, with notes on additional species (Coleoptera: Scirtidae). Lauterbornia 62: 79-88.

ZWICK P. \& ZWICK H. 2008a: Scirtes haemisphaericus uses macrophyte snorkels to pupate under water. With notes on pupae of additional European genera of Scirtidae (Coleoptera). Aquatic Insects 30: 83-95.

ZWICK P. \& ZWICK H. 2008b: Number of larval instars, early instar structure, and life history of Scirtes hemisphaericus (Coleoptera: Scirtidae) in central Germany. Lauterbornia 63: 87-99.

ZWICK P. \& ZWICK H. 2008c: Beitrag zur Morphologie, Systematik und Biologie mitteleuropäischer Scirtidae (Coleoptera). Entomologische Nachrichten und Berichte 52: 185-191.

ZWICK P. \& ZWICK H. 2010: The number of larval instars in some Central European marsh beetles (Coleoptera, Scirtidae). Entomologische Blätter 106: 431-441. 
